\title{
Short-term functional outcome in psychotic patients: results of the Turku early psychosis study (TEPS)
}

Raimo K. R. Salokangas ${ }^{1 *}$, Tiina From, Tuula Ilonen', Sinikka Luutonen ${ }^{1,2}$, Markus Heinimaa ${ }^{1}$, Reetta-Liina Armio ${ }^{1}$, Heikki Laurikainen', Maija Walta', Janina Paju' ${ }^{1}$, Anna Toivonen ${ }^{1}$, Päivi Jalo², Lauri Tuominen ${ }^{1,3}$ and Jarmo Hietala ${ }^{1,2}$

\begin{abstract}
Background: Functional recovery of patients with clinical and subclinical psychosis is associated with clinical, neuropsychological and developmental factors. Less is known about how these factors predict functional outcomes in the same models. We investigated functional outcomes and their predictors in patients with first-episode psychosis (FEP) or a confirmed or nonconfirmed clinical high risk of psychosis (CHR-P vs. CHR-N).

Methods: Altogether, 130 patients with FEP, 60 patients with CHR-P and 47 patients with CHR-N were recruited and extensively examined at baseline (T0) and 9 (T1) and 18 (T2) months later. Global Assessment of Functioning (GAF) at T0, T1 and T2 and psychotic, depression, and anxiety symptoms at T1 and T2 were assessed. Functional outcomes were predicted using multivariate repeated ANOVA.

Results: During follow-up, the GAF score improved significantly in patients with FEP and CHR-P but not in patients with CHR-N. A single marital status, low basic education level, poor work situation, disorganization symptoms, perceptual deficits, and poor premorbid adjustment in patients with FEP, disorganization symptoms and poor premorbid adjustment in patients with CHR-P, and a low basic education level, poor work situation and general symptoms in patients with CHR-N predicted poor functional outcomes. Psychotic symptoms at T1 in patients with FEP and psychotic and depression symptoms at $\mathrm{T} 1$ and anxiety symptoms at $\mathrm{T} 2$ in patients with CHR-P were associated with poor functioning.
\end{abstract}

Conclusions: In patients with FEP and CHR-P, poor premorbid adjustment and disorganization symptomatology are common predictors of the functional outcome, while a low education level and poor work situation predict worse functional outcomes in patients with FEP and CHR-N. Interventions aimed at improving the ability to work and study are most important in improving the functioning of patients with clinical or subclinical psychosis.

Keywords: Functional outcome, Psychotic disorders, Clinical high risk of psychosis, Premorbid adjustment, Disorganization symptoms, Negative symptoms

\footnotetext{
* Correspondence: Raimo.K.R.Salokangas@utu.fi

'Department of Psychiatry, University of Turku, Kunnallissairaalantie 20, FIN-20700 Turku, Finland

Full list of author information is available at the end of the article
}

(c) The Author(s). 2021 Open Access This article is licensed under a Creative Commons Attribution 4.0 International License, which permits use, sharing, adaptation, distribution and reproduction in any medium or format, as long as you give appropriate credit to the original author(s) and the source, provide a link to the Creative Commons licence, and indicate if changes were made. The images or other third party material in this article are included in the article's Creative Commons licence, unless indicated otherwise in a credit line to the material. If material is not included in the article's Creative Commons licence and your intended use is not permitted by statutory regulation or exceeds the permitted use, you will need to obtain permission directly from the copyright holder. To view a copy of this licence, visit http://creativecommons.org/licenses/by/4.0/. The Creative Commons Public Domain Dedication waiver (http://creativecommons.org/publicdomain/zero/1.0/) applies to the data made available in this article, unless otherwise stated in a credit line to the data. 


\section{Background}

Psychoses impose substantial human, medical, social and economic burdens on affected individuals, their families and society as a whole $[1,2]$ and are associated with a reduced life expectancy by 15-20 years [3]. Therefore, clarification of the factors affecting outcomes in patients with psychoses is of great importance.

The clinical outcomes of schizophrenia are still rather poor [4, 5], the need for care is high [6], and the ability to work is very low [7]. Compared to other psychotic disorders, schizophrenia is consistently characterized by poorer courses and outcomes [8]. Poor premorbid personal and psychosocial development, slow illness development, young age at the onset of illness, male gender, single marital status, lack of an interpersonal network, and alcohol and drug abuse are associated with poor outcomes, and among the clinical characteristics, severe negative symptoms, neurocognitive deficits and slow or partial recovery after the first illness episode are associated with poor outcomes [9-22].

In terms of neurocognitive deficits, the most pronounced impairments have been observed in processing speed and episodic memory [23-28]. However, during a long-term follow-up of patients with schizophrenia, baseline neurocognitive impairments did not correlate with the clinical outcome [29]. In addition, childhood adversities have been associated with psychotic disorders [30-33]. Less is known about their role in predicting the functional outcomes of patients with psychosis.

Studies of patients with a high risk of psychosis (CHRP) have mainly focused on the transition to psychosis and its prevention [34-36]. Since these earlier studies, the rate of onset of psychoses among patients with CHR-P has decreased, and is currently at the level of approximately $20 \%$ at the two-year follow-up [37, 38]. According to a meta-analysis, both psychological and pharmacological interventions appear to reduce or delay conversion to psychosis but rarely improve functional outcomes in relation to the control conditions [39].

Patients with CHR-P are characterized by many clinical disorders, including impairments in work or educational functioning, social functioning and quality of life [40]. In addition to brief limited psychotic symptoms, e.g., positive symptoms, bizarre thinking, schizotypal personality disorder/features, depression, and disorganization, neurocognitive deficits and poor psychosocial adjustment have been identified as risk factors for the transition to psychosis in patients with CHR-P [41-47].

As shown in various studies, processing speed, deficits in motor speed, verbal memory, verbal learning, verbal fluency and executive function are associated with the onset of psychosis and poor functioning [47-54]. According to a systematic review, negative and disorganization symptoms and cognitive deficits predate frank psychotic symptoms, and are risk factors for poor functioning [55]. Additionally, patients with CHR-P often report high levels of childhood adversities [56, 57]. In follow-up studies, childhood adversities have predicted depression, poor social functioning and suicidal thinking $[58,59]$.

Premorbid psychosocial development and its role as a predictor of the functional outcome have received less attention. In a study of patients with CHR-P, premorbid psychosocial adjustment, baseline negative symptoms and poor working/schooling situations predicted poor functional outcomes during follow-up [60]. Additionally, in other studies, negative symptoms and impairments in role and social functioning have predicted poor functional outcomes at follow-up [52, 53, 61].

The literature described above indicates that a large number of individual factors are associated with functional outcomes in patients with clinical or subclinical psychotic symptoms. The effects of these factors probably overlap with each other. Less is known about which of them exerts an independent effect on patients' functional outcomes.

\section{Aims of the study}

In this study, which is part of the Turku Early Psychosis Study (TEPS), we aimed to describe our study samples and investigate 1 ) the short-term (up to approximately 18 months) functional outcomes of patients with firstepisode psychosis (FEP) or confirmed (CHR-P) or nonconfirmed clinical high risk of psychosis (CHR-N) and 2) the factors predicting functional outcomes in these three patient groups. We hypothesized that if positive psychotic symptoms effect on follow-up functioning, functional outcome will be poorer in patients with FEP than in patients with CHR.

\section{Materials and methods}

In the Supplementary Material, we have described the methods of the TEPS project in detail. Here, we concentrate on the methods of the TEPS functional outcome study comprising patients with FEP, CHR-P and CHR$\mathrm{N}$. The TEPS study program was carried out in accordance with the latest version of the Declaration of Helsinki. The study design and protocols were approved by the ethics committee of Turku University Hospital. Written informed consent was obtained from participants after the procedure had been fully explained to them.

\section{Participants}

The study patients aged 18 to 50 years were recruited from mental hospitals $(N=183)$, psychiatric outpatient care units $(n=101)$ and primary care stations $(n=19)$ of 
the Turku University Hospital District in Finland between October 2011 and December 2017.

When an eligible patient attended psychiatric/primary care services for the first time, the personnel completed a screen, determining whether the patient was possibly psychotic or at high risk of psychosis. The TEPS study group assessed the completed screens and invited the patients who possibly fulfilled the inclusion criteria to participate in the study examinations. FEP was defined based on the Structured Clinical Interview for DSM-IV [62] criteria and included schizophrenia, delusional and bipolar psychoses, acute transient psychoses and other psychoses. CHR-P was defined based on the ultrahighrisk criteria Attenuated Psychotic Symptoms, Brief Limited Psychotic Symptoms, and Genetic risk and reduction of function assessed with the 3.0/5.0 version of the Structured Interview for Prodromal Syndromes (SIPS/ SOPS), including Global Assessment of Functioning (GAF) [63, 64]. The patients who were at high risk of psychosis according to the health-care personnel's clinical impression but who did not fulfil the SIPS/SOPS criteria in the diagnostic examination were patients with a nonconfirmed high risk of psychosis (CHR-N). Exclusion criteria for study patients were a previous psychotic disorder and IQ $<70$. The final TEPS sample comprises 130 patients with FEP, 60 patients with CHR-P, and 47 patients with CHR-N.

\section{Baseline examinations}

At baseline, the study patients underwent extensive examinations (Supplementary Material). For this outcome study, in addition to socioeconomic background, patients' premorbid adjustment (PAS) [65], Axis I diagnosis (SCID-I; DSM-IV) [62] and clinical high risk of psychosis (SIPS/SOPS, including GAF) $[62,63]$ were obtained in interviews. Additionally, patients completed questionnaires on childhood adverse and traumatic experiences (TADS) $[66,67]$ and social support or confidants (PSS-R) [68].

PAS evaluates difficulties in individuals' premorbid adjustment (rated from 0 to 6 points) during four time domains: childhood (up to 11 years), early (12-15 years) and late adolescence (16-18 years) and adulthood (19+ years). Because not all participants had reached adulthood, only the childhood, early and late adolescence PAS domain scores were used in analyses.

In SIPS/SOPS, 5 positive, 6 negative, 4 disorganization and 4 general symptoms, schizotypal personality disorder and functioning (GAF), are assessed [62, 63]. In the present study, we used sums of positive, negative, disorganization and general symptoms as clinical predictors.

The TADS, which has been validated in a general population sample [67], produces information on five core domains: emotional abuse (EmoAb), physical abuse (PhyAb), sexual abuse (SexAb), emotional neglect (Emo$\mathrm{Neg}$ ) and physical neglect (PhyNeg).

The social support questionnaire (PSS-R) [68] comprises lists of 12 questions on support received $(0=$ never, $1=$ hardly ever, $2=$ sometimes, $3=$ most of time and $4=$ all the time) from family and friends. The sum score (range 0-48) was used as an indicator of confidant support.

Neuropsychological tests were not performed before the patients with psychosis recovered from their manifest psychosis, usually 3 to 4 weeks after admission to a hospital ward. The following domains and tests were used: estimate of premorbid cognitive functioning ( $\mathrm{Vo}$ cabulary, WAIS-III) [69], letter (S) and category (animals) fluency [70, 71], attention/vigilance (Trail Making A/B) [72], speed of processing (Digit Symbol, WAIS-III), verbal and visual working memory (Letter-Number Span, WAIS-III and Spatial Span WMS-R) [73], verbal learning (Hopkins Verbal Learning Test-Revised, HVLT) [74], visual learning (Brief Visuospatial Memory testRevised, BVMT-R) [75], reasoning and problem solving (Neuropsychological Assessment Battery, Mazes) [76], perceiving and forming concepts in a complex problem solving situation (Rorschach Comprehensive System, RCS) [77, 78], executive function (Wisconsin Card Sorting Test, WCST) [79], and social cognition (Mayer-Salovey-Caruso Emotional Intelligence Test, MSCEIT, Managing Emotions, D and H) [80].

\section{Follow-up examinations}

When nine (T1) and 18 (T2) months was elapsed from the baseline examination, patients were invited for extensive follow-up examinations (Supplementary Material). For this outcome study, GAF, as well as the occurrence of psychotic (yes/no), depression (yes/ no) and anxiety (yes/no) symptoms were recorded at the follow-up time points (T1 and T2), and the transition to psychosis was detected [43]. Due to dropouts, information regarding both functioning (GAF) and psychiatric symptoms at follow-up visits was supplemented by scrutinizing patients' medical case notes and by telephone interviews of patients and/or their relatives and/or their doctors (RKRS), as described in detail in the Supplementary Material. Symptom severity was not assessed.

\section{Statistical analyses}

First, distributions of background factors were crosstabulated, and means (SD) of GAF, SIPS, TADS, confidant support, PAS scores and neuropsychological test scores were calculated by diagnostic groups and tested using the Chi-square test and ANOVA. Repeated measures ANOVA over the whole study period (GAFT0, 
GAFT1 and GAFT2) was calculated for the diagnostic group and each baseline characteristic, SIPS and TADS domain, three PAS domain scores and for each neuropsychological test.

Using multivariate repeated-measures ANOVAs, functioning over the study period (GAFT0, GAFT1 and GAFT2) was explained by blocks of independent variables: 1) diagnosis and background factors, 2) SIPS domain scores (positive, negative, disorganization and general) and confidant support, 3) neuropsychological test scores, 4) TADS domains and 5) PAS domain scores. At each stage, non-significant $(p>0.1)$ factors were omitted, and the remaining variables were included in the model with the next block of variables. In the final model, only the factors with a significant association $(p<0.05)$ with functioning were included in the equation. Thereafter, psychotic, depression and anxiety symptoms at $\mathrm{T} 1$ and $\mathrm{T} 2$ were entered into the final model to analyse how follow-up symptoms change the explanatory power of the model. Analyses were performed for all study subjects and separately for patients with FEP, CHR-P and CHR-N. Data were analysed using Statistical Program for the Social Sciences (SPSS) v24.0, and $p$ values $<0.05$ were considered significant.

\section{Results}

\section{Baseline sociodemographic and clinical characteristics}

In terms of sociodemographic factors and social support received, no differences were observed between patients with FEP, CHR-P and CHR-N. One-third of patients with FEP had affective psychosis, and twothirds had non-affective psychosis. The majority of the patients with CHR-P and CHR-N suffered from depressive and anxiety disorders; the difference was not significant $(p=0.369)$ (Table 1). SIPS psychotic symptoms, which were used as diagnostic criteria for FEP, CHR-P and CHR-N, increased linearly from CHR-N to CHR-P $(p<0.001)$ and from CHR-P to FEP $(\mathrm{p}<0.001)$. Differences in disorganization symptoms between patients with FEP and CHR-N ( $p=$ $0.001)$ and between patients with CHR-P and CHR-N $(p=0.046)$ were also significant. In terms of negative and generalized symptoms, TADS domains and PAS domain scores, no significant differences were observed between diagnostic groups (Table 1).

The use of mental services and the duration of symptoms were investigated to describe patients' recent clinical history. Before baseline admission or outpatient visits, $65.4 \%$ of patients with FEP, $76.7 \%$ of patients with CHR-P and $85.1 \%$ of patients with CHR-N sought help for their mental problems ( $p=$ $0.024)$. At baseline, $44.4 \%$ of patients reported anxiety, and $40.1 \%$ reported depression symptoms $(p>0.1)$. In patients with FEP, delusional (41.5\%), hallucinatory
(37.7\%) and disorganization symptoms (33.8\%) were more prevalent (ANOVA: $p=0.013, p=0.001$, and $p=0.011$, respectively) than in patients with CHR-P (23.3, 13.3, and $18.3 \%$, respectively) and patients with CHR-N (23.4, 19.1, and 14.9\%, respectively), including subclinical symptoms. The mean duration of symptoms was 555 (SD 1302) days for anxiety, 337 (SD 649) days for depression, 181 (SD 691) days for delusions, 88 (SD 279) days for hallucinations and 197 (SD 770) days for disorganization. No differences were observed between diagnostic groups. Alcohol was related to the onset of symptoms in $6.8 \%$ of patients and substance use was related in $5.5 \%$ of patients, but no differences were observed between patient groups. The FEP sample included three patients with substance-induced psychoses.

In general, patients with FEP had more difficulties in maintaining attention, processing speed, working memory, verbal and visual learning, reasoning and problem solving than patients with CHR-P or CHR$\mathrm{N}$; differences between patients with CHR-P and CHR-N were nonsignificant (Table 2). In WCST and RCS, patients with FEP exhibited poorer performance than patients with CHR-N, and in RCS, patients with CHR-P patients exhibited poorer performance than patients with CHR-N (Table 2).

\section{Baseline drug treatment}

The study patients did not participate in any specific trial intervention; their treatment followed usual clinical practice, including supportive therapy and drug treatment. By the time of baseline examination, patients with FEP had received neuroleptic drugs (87.7\%) more often $(p<0.001)$ and antidepressants $(47.7 \%)$ less often $(p=$ $0.001)$ than patients with CHR-P (45.0 and 48.3\%) and CHR-N (31.9 and 53.2\%). Notably, 20.3\% of all patients received anxiolytics, 9.3\% received hypnotics and 6.3\% were treated with mood stabilizers, with no differences between diagnostic groups.

\section{Functioning at baseline and follow-ups}

A comparison of patients' functioning, as assessed using the Global Assessment of Functioning (GAF), between diagnostic groups showed that at baseline, the functioning of patients with FEP was poorer than that of patients with CHR-P $(p=0.004)$ and CHR-N $(p<0.001)$. The difference between patients with CHR-P and CHR-N was not significant $(p=0.072)$. During follow-up, the functioning of patients with FEP and CHR-P improved significantly, but not that of patients with CHR-N (Table 3). At $\mathrm{T} 1$ and $\mathrm{T} 2$, no significant differences in functioning were observed between diagnostic groups (Table 3). 
Table 1 Socio-demographic background and baseline characteristics of the TEPS sample

\begin{tabular}{|c|c|c|c|c|c|}
\hline & FEP $^{a}$ & CHR-Pb & CHR-N ${ }^{c}$ & All & $p$ \\
\hline Gender (\%) & $n=130$ & $n=60$ & $n=47$ & $n=237$ & 0.573 \\
\hline Male & 56.9 & 53.3 & 55.8 & 55.8 & \\
\hline Female & 43.1 & 46.7 & 44.2 & 44.2 & \\
\hline Age (years) & $n=130$ & $n=60$ & $n=47$ & $n=237$ & 0.289 \\
\hline $18-23$ & 37.7 & 53.3 & 46.8 & 43.5 & \\
\hline $24-29$ & 33.1 & 23.3 & 23.4 & 28.7 & \\
\hline $30-49$ & 29.2 & 23.3 & 29.8 & 27.8 & \\
\hline mean (SD) & 26.5(5.9) & $25.0(6.2)$ & 27.1(7.9) & $26.3(6.4)$ & 0.195 \\
\hline Marital status (\%) & $n=130$ & $n=60$ & $n=47$ & $n=237$ & 0.536 \\
\hline Single & 72.3 & 71.7 & 63.8 & 70.5 & \\
\hline Ever married/divorced & 27.7 & 28.3 & 36.2 & 29.5 & \\
\hline Living with & $n=130$ & $n=60$ & $n=47$ & $n=237$ & 0.960 \\
\hline Alone & 47.7 & 45.0 & 46.8 & 46.8 & \\
\hline Own family/children & 30.0 & 30.0 & 31.9 & 30.4 & \\
\hline Parents/sisters & 16.2 & 20.0 & 12.8 & 16.5 & \\
\hline Other persons & 6.2 & 5.0 & 8.5 & 6.3 & \\
\hline Basic education (\%) & $n=130$ & $n=60$ & $n=47$ & $n=237$ & 0.490 \\
\hline Comprehensive school or less & 40.0 & 41.7 & 44.7 & 41.4 & \\
\hline High school & 13.8 & 6.7 & 6.4 & 10.5 & \\
\hline College & 46.2 & 51.7 & 48.9 & 48.1 & \\
\hline Professional education (\%) & $n=130$ & $n=60$ & $n=47$ & $n=237$ & 0.797 \\
\hline None & 43.8 & 48.3 & 42.6 & 44.7 & \\
\hline Vocational school & 41.5 & 43.3 & 42.6 & 42.2 & \\
\hline University & 14.6 & 8.3 & 14.9 & 13.1 & \\
\hline Years of education; mean (SD) & 13.8(3.1) & $13.2(2.9)$ & $13.9(3.4)$ & 13.7(3.1) & 0.382 \\
\hline Work situation (\%) & $n=130$ & $n=60$ & $n=47$ & $n=237$ & 0.574 \\
\hline Employed & 60.0 & 58.3 & 61.7 & 59.9 & \\
\hline Unemployed & 19.2 & 30.0 & 21.3 & 22.4 & \\
\hline Sick leave & 10.8 & 6.7 & 6.4 & 8.9 & \\
\hline Temporary retirement & 10.0 & 5.0 & 10.6 & 8.9 & \\
\hline Confident support (score) & $n=104$ & $n=48$ & $n=42$ & $n=194$ & \\
\hline mean, SD & $31.4(11.5)$ & $27.4(10.7)$ & $29.7(7.7)$ & $30.0(10.7)$ & 0.102 \\
\hline SCID Diagnosis (\%) & $n=130$ & $n=60$ & $n=47$ & $n=237$ & $<0.001$ \\
\hline No & 0.0 & 8.3 & 6.4 & 3.4 & \\
\hline Bipolar & 16.9 & 3.3 & 8.5 & 11.8 & \\
\hline Depression & 16.9 & 56.7 & 63.8 & 36.3 & \\
\hline Nonaffective Psychosis & 66.2 & 5.0 & 0.0 & 37.6 & \\
\hline Anxiety & 0.0 & 26.7 & 21.3 & 11.0 & \\
\hline SIPS symptom score mean (SD) & $n=125$ & $n=60$ & $n=47$ & $n=232$ & \\
\hline Positive (0-30) & $16.5(5.3)$ & 10.6(5.9) & $5.9(4.2)$ & $12.8(6.4)$ & $<0.001$ \\
\hline Negative (0-30) & 11.0(7.3) & 11.4(6.6) & $10.2(6.1)$ & $10.9(6.8)$ & 0.645 \\
\hline Disorganized (0-24) & $5.4(4.1)$ & $4.8(3.5)$ & $3.4(2.3)$ & $4.9(3.7)$ & 0.006 \\
\hline General (0-24) & $6.8(4.6)$ & $7.7(3.3)$ & $6.3(3.8)$ & $6.9(4.1)$ & 0.166 \\
\hline
\end{tabular}


Table 1 Socio-demographic background and baseline characteristics of the TEPS sample (Continued)

\begin{tabular}{|c|c|c|c|c|c|}
\hline & FEP $^{a}$ & CHR-Pb & CHR-N ${ }^{\mathrm{c}}$ & All & $p$ \\
\hline TADS score mean (SD) & $n=107$ & $n=48$ & $n=40$ & $n=195$ & \\
\hline EmoAb (1-5) & $4.7(4.3)$ & $5.3(4.4)$ & $5.4(4.8)$ & $5.0(4.4)$ & 0.586 \\
\hline PhyAb (1-5) & $1.7(2.1)$ & $1.8(2.6)$ & 2.3(3.9) & $1.9(2.7)$ & 0.508 \\
\hline SexAb (1-5) & $1.2(3.1)$ & $0.6(1.6)$ & $1.2(3.9)$ & $1.1(3.0)$ & 0.520 \\
\hline EmoNeg (1-5) & $6.8(5.0)$ & $7.5(5.1)$ & $8.3(4.1)$ & $7.3(4.9)$ & 0.241 \\
\hline PhyNeg (1-5) & $3.4(2.8)$ & $3.3(3.1)$ & $4.4(3.5)$ & $3.5(3.1)$ & 0.156 \\
\hline PAS score mean (SD) & $n=124$ & $n=57$ & $n=47$ & $n=228$ & \\
\hline-11 years $(0-24)$ & $6.2(3.6)$ & $6.8(3.3)$ & $6.6(3.6)$ & $6.5(3.5)$ & 0.495 \\
\hline $12-15$ years $(0-30)$ & $10.1(5.2)$ & $10.8(4.9)$ & $10.0(4.1)$ & 10.3(4.9) & 0.669 \\
\hline $16-18$ years $(0-30)$ & $10.9(5.6)$ & $10.9(5.9)$ & 10.4(3.8) & $10.8(5.3)$ & 0.839 \\
\hline
\end{tabular}

${ }^{\mathrm{a} F i r s t-e p i s o d e ~ p s y c h o s i s ~}$

${ }^{\mathrm{b} C o n f i r m e d ~ c l i n i c a l ~ h i g h-r i s k ~ t o ~ p s y c h o s i s ~}$

${ }^{c}$ Nonconfirmed clinical high risk to psychosis

EmoAb Emotional abuse, PhyAb Physical abuse, SexAb Sexual abuse

EmoNeg Emotional neglect, PhyAb Physical Abuse, PAS Premorbid adjustment

\section{Univariate prediction of functioning}

First, repeated-measures ANOVA separately predicted follow-up functional outcomes (GAFT0, GAFT1 and GAFT2) with three sets of variables: 1. diagnostic groups and baseline sociodemographic factors, 2. SIPS symptoms, TADS domains and PAS domains, and 3. neuropsychological test scores. The diagnostic groups (FEP/ CHR-P/CHR-N $)(p=0.064)$ and SCID diagnosis groups $(p=0.140)$ were not significantly associated with the functional outcome. Among the baseline characteristics, female gender $(p=0.001)$, nonsingle marital status $(p=$ $0.005)$, confidant support $(p=0.005)$, good basic $(p<$ $0.001)$ and professional education $(\mathrm{p}<0.001)$ and a good work situation $(\mathrm{p}<0.001)$ predicted good functioning (Table 4). In patients with FEP, these associations were similar to those in the entire patient sample. Only gender and work situation in patients with CHR-P and basic and professional education and the work situation in patients with CHR-N were associated with functioning at follow-up (Supplementary Table 1).

All SIPS symptoms, PAS domains and PhyAb from TADS were significantly associated with functioning (Supplementary Table 2). In patients with FEP, all SIPS symptoms and all PAS domains, in patients with CHR-P, SIPS negative and disorganized symptoms, PhyAb and all PAS domains and in patients with CHR-N, all SIPS symptoms, EmoAb and PhyAb associated significantly with follow-up functioning. In patients with FEP and CHR-P, but not in patients with CHR-N, both childhood, early and late adolescence PAS scores were associated with follow-up functioning (Supplementary Table 2).

From neuropsychological tests, WAIS IQ (vocabulary), word fluency, divided attention (TMTB), processing speed, verbal and visual working memory, verbal and visual learning and problem solving were associated with functioning. From the WCST, the number of errors, conceptual responses and from RCS test perceptual problems (PTI, X-\%, XA\%, and WDA\%) associated with functioning. Vocabulary, word fluency, visual working memory, visual learning, and perceptual disturbances in patients with FEP; sustained attention (TMTA), verbal working memory and WCST scores in patients with CHR-P; and vocabulary and attention (TMTA) in patients with CHR-N were associated with functioning (Supplementary Table 3).

\section{Multivariate prediction of functioning at follow-up}

Next, the functional outcome (GAFT0, GAFT1 and GAFT2) was predicted by all variables in multivariate repeated ANOVAs. Predictors were added to the models in order as described in the Methods. In the entire patient sample, a good basic education and work situation, lack of disorganization symptoms and perceptual deficits, and good premorbid late adolescence adjustment predicted good functioning. Together, these factors explained $38.8 \%$ of the variance in functioning (Table 4). When the baseline drugs were added into the model (Table 4), only neuroleptics associated negatively with the functional outcome $\left(p=0.003, \eta^{2}=0.042\right)$ and the model did not change essentially. The effect of perceptual deficits was not anymore significant $\left(p=0.071, \eta^{2}=0.016\right)$.

In sensitivity analyses of patients with FEP, marital status $(p=0.001)$, basic education $(p=0.012)$, work situation $(p=0.002)$, SIPS disorganization symptoms $(p<$ $0.001)$, perceptual problems (XA\%; $p=0.028)$ and late adolescence PAS scores $(p=0.003)$ were significantly associated with functioning (Supplementary Table 4a). In patients with CHR-P, only baseline SIPS disorganization 
Table 2 Neuropsychological tests by diagnostic groups

\begin{tabular}{|c|c|c|c|c|c|c|c|c|c|c|c|c|}
\hline & \multicolumn{2}{|c|}{$\begin{array}{l}\text { FEP }^{a} \\
(n=119)\end{array}$} & \multicolumn{2}{|c|}{$\begin{array}{l}\text { CHR-Pb } \\
(n=54)\end{array}$} & \multicolumn{2}{|c|}{$\begin{array}{l}\text { CHR-N }{ }^{c} \\
(n=46)\end{array}$} & \multicolumn{2}{|c|}{ All $(n=219)$} & \multirow[b]{2}{*}{ p1 } & \multirow{2}{*}{$\begin{array}{l}\text { FEP/CHR- } \\
\text { P } \\
\text { p2 }\end{array}$} & \multirow{2}{*}{$\begin{array}{l}\text { FEP/CHR- } \\
\mathrm{N} \\
\text { p3 }\end{array}$} & \multirow{2}{*}{$\begin{array}{l}\text { CHR-P/CHR- } \\
\mathrm{N} \\
\mathrm{p} 4\end{array}$} \\
\hline & Mean & SD & Mean & SD & Mean & SD & Mean & SD & & & & \\
\hline \multicolumn{13}{|l|}{ Verbal skills } \\
\hline WAIS III Vocabulary & 42.61 & 10.84 & 42.80 & 10.57 & 43.07 & 10.85 & 50.14 & 7.54 & 0.970 & 0.914 & 0.806 & 0.901 \\
\hline MCCB Category Fluency & 22.23 & 5.71 & 22.98 & 5.24 & 24.52 & 7.39 & 24.36 & 6.12 & 0.090 & 0.444 & 0.029 & 0.202 \\
\hline MCCB S-words & 15.11 & 5.56 & 15.54 & 5.48 & 16.83 & 4.45 & 16.51 & 5.40 & 0.180 & 0.625 & 0.065 & 0.229 \\
\hline \multicolumn{13}{|l|}{ Attention/vigilance } \\
\hline TMT-A & 32.94 & 10.18 & 28.17 & 8.33 & 31.52 & 10.93 & 29.70 & 9.83 & 0.015 & 0.004 & 0.411 & 0.093 \\
\hline TMT-B & 92.18 & 66.00 & 86.24 & 82.34 & 66.50 & 38.08 & 75.81 & 58.28 & 0.082 & 0.583 & 0.026 & 0.137 \\
\hline \multicolumn{13}{|l|}{ Speed of processing } \\
\hline WAIS III Digit Symbol & 66.37 & 15.78 & 73.44 & 16.85 & 74.59 & 15.54 & 75.24 & 16.97 & 0.002 & 0.008 & 0.003 & 0.722 \\
\hline \multicolumn{13}{|l|}{ Working memory } \\
\hline WAIS III Letter-Number Span & 9.97 & 2.22 & 10.59 & 2.02 & 11.17 & 2.34 & 10.94 & 2.38 & 0.006 & 0.088 & 0.002 & 0.189 \\
\hline WMS-R Spatial Span & 16.87 & 3.01 & 17.57 & 2.95 & 17.22 & 2.15 & 17.63 & 2.88 & 0.313 & 0.126 & 0.477 & 0.523 \\
\hline \multicolumn{13}{|l|}{ Verbal learning } \\
\hline HVLT immediate & 25.94 & 4.29 & 27.31 & 4.60 & 28.89 & 3.95 & 27.79 & 4.43 & $\begin{array}{l}< \\
0.001\end{array}$ & 0.053 & $<0.001$ & 0.069 \\
\hline HVLT delayed & 9.18 & 2.12 & 10.19 & 1.90 & 10.35 & 1.72 & 10.04 & 1.95 & $\begin{array}{l}< \\
0.001\end{array}$ & 0.002 & 0.001 & 0.684 \\
\hline \multicolumn{13}{|l|}{ Visual learning } \\
\hline MCCB BVMT-R & 24.37 & 6.98 & 26.96 & 6.43 & 26.65 & 6.51 & 26.87 & 6.59 & 0.029 & 0.020 & 0.053 & 0.819 \\
\hline \multicolumn{13}{|l|}{ Reasoning and problem solving } \\
\hline MCCB NAB Mazes & 20.43 & 4.89 & 22.07 & 3.59 & 22.24 & 4.15 & 21.78 & 4.18 & 0.018 & 0.025 & 0.020 & 0.854 \\
\hline \multicolumn{13}{|l|}{ WCST } \\
\hline Total number of errors & 30.20 & 24.54 & 28.24 & 19.23 & 22.35 & 18.18 & 28.07 & 22.22 & 0.125 & 0.589 & 0.042 & 0.185 \\
\hline Perseverative responses & 18.73 & 19.06 & 16.63 & 12.98 & 12.91 & 11.21 & 16.99 & 16.39 & 0.122 & 0.433 & 0.041 & 0.257 \\
\hline Perseverative errors & 16.36 & 15.00 & 15.11 & 10.91 & 11.87 & 9.47 & 15.11 & 13.12 & 0.143 & 0.560 & 0.049 & 0.218 \\
\hline Percent conceptual level responses & 64.51 & 21.74 & 66.07 & 16.94 & 71.46 & 17.17 & 66.36 & 19.84 & 0.130 & 0.630 & 0.044 & 0.176 \\
\hline Number of categories completed & 4.96 & 1.68 & 5.11 & 1.42 & 5.39 & 1.31 & 5.09 & 1.55 & 0.272 & 0.547 & 0.108 & 0.368 \\
\hline \multicolumn{13}{|l|}{ Ro-Exner (RCS) } \\
\hline Perceptual thinking index (PTI) & 1.25 & 1.34 & 1.37 & 1.19 & 0.70 & 1.07 & 1.16 & 1.27 & 0.016 & 0.566 & 0.011 & 0.008 \\
\hline Distorted perception (X-\%) & 0.28 & 0.11 & 0.28 & 0.09 & 0.21 & 0.08 & 0.26 & 0.10 & 0.001 & 0.824 & 0.001 & 0.002 \\
\hline Incoherent thinking (WSum6) & 9.90 & 8.70 & 9.69 & 7.56 & 7.02 & 6.50 & 9.24 & 8.06 & 0.108 & 0.871 & 0.040 & 0.099 \\
\hline Appropriate answers (XA\%) & 0.70 & 0.12 & 0.70 & 0.09 & 0.76 & 0.09 & 0.71 & 0.11 & 0.002 & 0.923 & 0.001 & 0.003 \\
\hline $\begin{array}{l}\text { Extended appropriate answers } \\
\text { (WDA\%) }\end{array}$ & 0.73 & 0.12 & 0.73 & 0.09 & 0.79 & 0.08 & 0.75 & 0.11 & 0.003 & 0.902 & 0.001 & 0.005 \\
\hline
\end{tabular}

${ }^{\mathrm{a}}$ First episode psychosis

${ }^{b}$ Confirmed clinical high risk to psychosis

${ }^{c}$ Nonconfirmed clinical high risk to psychosis; $\mathrm{p} 1=$ ANOVA for all patients; $\mathrm{p} 2=$ ANOVA for FEP/CHR-P; $\mathrm{p} 3=\mathrm{ANOVA}$ for FEP/CHR-N; $\mathrm{p} 4=\mathrm{ANOVA}$ for CHR-P/CHR-N

symptoms $(p=0.008)$ and childhood PAS scores $(p=$ 0.004 ) were associated with functioning (Supplementary Table 4b), whereas in patients with CHR-N, basic education $(p=0.001)$, work situation $(p=0.009)$ and SIPS general symptoms $(p=0.006)$ were associated with functioning (Supplementary Table 4c). The proportion of variance explained was $55.6 \%$ for patients with FEP, $24.2 \%$ for patients with CHR-P, and $72.5 \%$ for patients with CHR-N. In the patients with FEP, baseline medication did not associate with the functional outcome. In the patients with CHR-P, baseline anxiolytics associated negatively with the functional outcome $\left(p=0.016, \eta^{2}=\right.$ 0.104 ) and the effect of late adolescence PAS became insignificant $\left(p=0.053, \eta^{2}=0.069\right)$. In the patients with CHR-N, baseline medication had no significant association with the functional outcome. 
Table 3 Patients' functioning at baseline (T0), at 9 months (T1) and at 18 months follow-ups (T2) (A) and paired differences for functioning at baseline (GAFT0), at 9 months (GAFT1) and at 18 months follow-ups (GAFT2) (B) by diagnostic groups

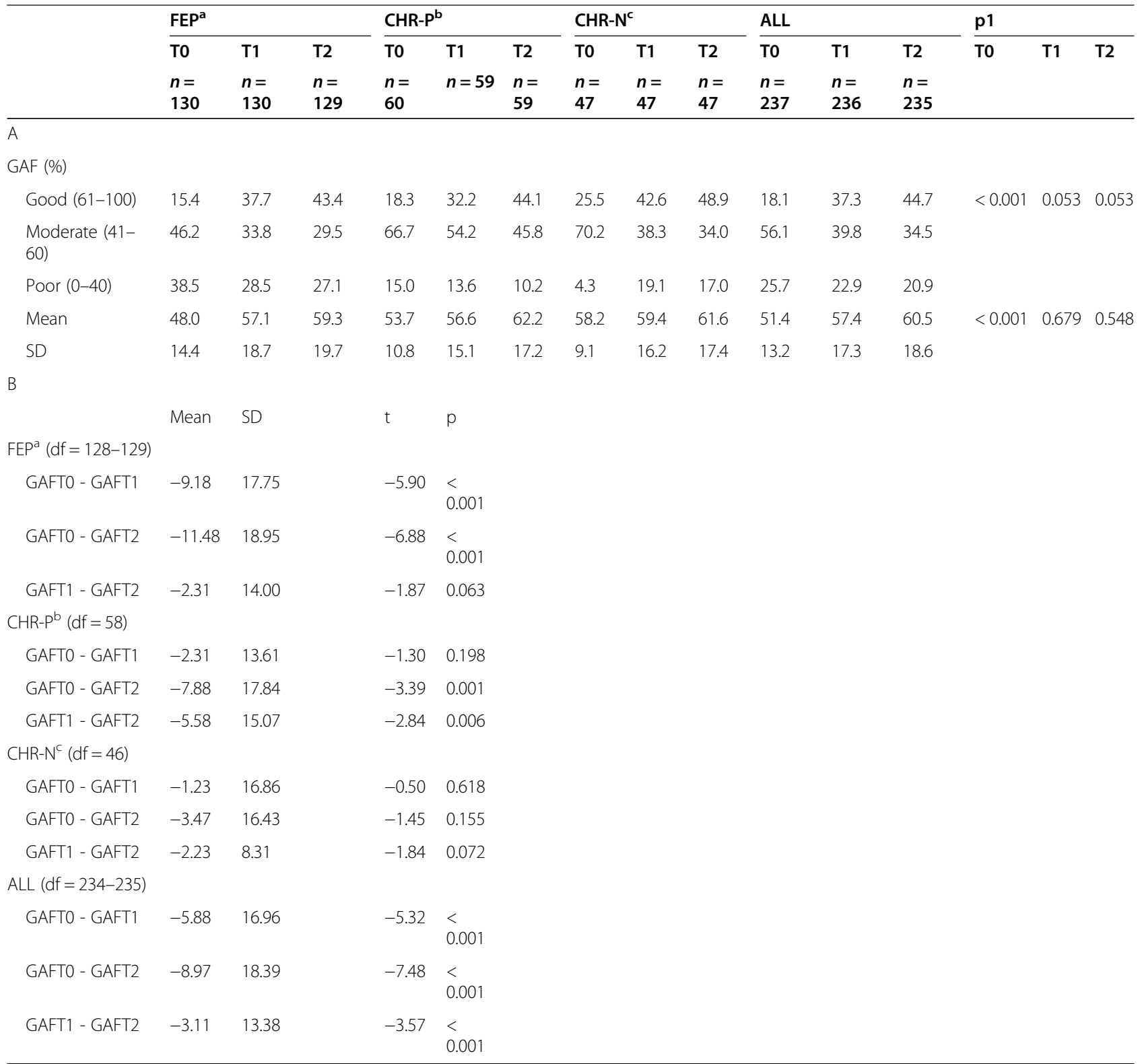

${ }^{a}$ First-episode psychosis

${ }^{\mathrm{b}}$ Confirmed clinical high-risk to psychosis

${ }^{c}$ Nonconfirmed clinical high risk to psychosis. p1 = significance between FEP, CHR-P and CHR-N

In the final stage, psychotic, depressive and anxiety symptoms occurring at T1 and T2 were included in the outcome models. In the entire patient sample, T1 psychotic symptoms $(p<0.001)$, T2 depression $(p=0.001)$ and T2 anxiety symptoms $(p=0.006)$ were entered into the equation, and the proportion of variance explained increased from 38.8 to $63.3 \%$. Only T1 psychotic symptoms $(p<0.001)$ in patients with FEP; T1 psychotic symptoms $(p=0.023)$, T1 depression $(p=0.002)$ and T2 anxiety symptoms $(p<$
0.001) in patients with CHR-P; and T2 depression $(p=0.046)$ symptoms in patients with CHR-N were entered into the equation. The proportion of variance in functioning explained increased in patients with FEP (from 55.6 to $73.8 \%$ ) and CHR-P (from 24.2 to $90.0 \%$ ), but not in patients with CHR-N (from 72.5 to $68.5 \%$ ). Transitions to psychosis (CHRP: $13 / 60$ [21.7\%]; CHR-N: 6/47 [12.8\%]) were not associated with functional outcomes in either $\mathrm{CHR}$ group. 
Table 4 Repeated measures ANOVA of functional outcome for all patients ( $n=213$ )

\begin{tabular}{|c|c|c|c|c|c|}
\hline Between subjects effect & df & $\mathbf{F}$ & $\mathrm{p}$ & Par. $n^{2}$ & \\
\hline Basic education & 2 & 6.22 & 0.002 & 0.06 & \\
\hline Work situation & 3 & 9.29 & $<0.001$ & 0.12 & \\
\hline SIPS disorganized symptoms & 1 & 24.62 & $<0.001$ & 0.11 & \\
\hline Appropriate answers (XA\%) & 1 & 4.14 & 0.043 & 0.02 & \\
\hline Late adolescence PAS & 1 & 18.29 & $<0.001$ & 0.08 & \\
\hline Parameter estimations & $\mathrm{B}$ & $t$ & $p$ & C195\% & \\
\hline \multicolumn{6}{|l|}{ Functioning at baseline (GAFT0) } \\
\hline Comprehensive school or less & 0.81 & 0.49 & 0.627 & -2.47 & 4.09 \\
\hline High school & -2.73 & -1.09 & 0.277 & -7.69 & 2.22 \\
\hline College & - & & & & \\
\hline Employed & 9.60 & 3.53 & 0.001 & 4.24 & 14.96 \\
\hline Unemployed & 8.31 & 2.78 & 0.006 & 2.42 & 14.21 \\
\hline Sick leave & 3.42 & 0.96 & 0.337 & -3.58 & 10.42 \\
\hline Temporary retirement & - & & & & \\
\hline SIPS disorganized symptoms & -1.30 & -5.81 & $<0.001$ & -1.75 & -0.86 \\
\hline Appropriate answers (XA\%) & 20.32 & 2.85 & 0.005 & 6.24 & 34.40 \\
\hline Late adolescence PAS & -0.23 & -1.48 & 0.140 & -0.55 & 0.08 \\
\hline \multicolumn{6}{|l|}{ Functioning at 9 months (GAFT1) } \\
\hline Comprehensive school or less & -4.44 & -2.05 & 0.042 & -8.72 & -0.17 \\
\hline High school & -9.31 & -2.85 & 0.005 & -15.76 & -2.86 \\
\hline College & - & & & & \\
\hline Employed & 11.89 & 3.36 & 0.001 & 4.90 & 18.87 \\
\hline Unemployed & 5.13 & 1.32 & 0.189 & -2.55 & 12.81 \\
\hline Sick leave & 6.23 & 1.35 & 0.180 & -2.89 & 15.34 \\
\hline Temporary retirement & - & & & & \\
\hline SIPS disorganized symptoms & -1.01 & -3.46 & 0.001 & -1.59 & -0.44 \\
\hline Appropriate answers (XA\%) & 14.65 & 1.58 & 0.117 & -3.68 & 32.99 \\
\hline Late adolescence PAS & -0.75 & -3.64 & $<0.001$ & -1.15 & -0.34 \\
\hline \multicolumn{6}{|l|}{ Functioning at 18 months (GAFT2) } \\
\hline Comprehensive school or less & -5.99 & -2.52 & 0.012 & -10.67 & -1.31 \\
\hline High school & -11.62 & -3.24 & 0.001 & -18.68 & -4.55 \\
\hline College & - & & & & \\
\hline Employed & 14.37 & 3.71 & $<0.001$ & 6.72 & 22.01 \\
\hline Unemployed & 5.42 & 1.27 & 0.205 & -2.99 & 13.82 \\
\hline Sick leave & 8.80 & 1.74 & 0.083 & -1.18 & 18.79 \\
\hline Temporary retirement & - & & & & \\
\hline SIPS disorganized symptoms & -0.81 & -2.53 & 0.012 & -1.44 & -0.18 \\
\hline Appropriate answers (XA\%) & 5.79 & 0.57 & 0.570 & -14.28 & 25.87 \\
\hline Late adolescence PAS & -0.91 & -4.05 & $<0.001$ & -1.36 & -0.47 \\
\hline
\end{tabular}

Par. $\eta^{2}=$ Partial Eta Squared. Significant $\mathrm{p}$ values bolded

\section{Discussion}

At the time of a visit to receive treatment, patients with FEP, CHR-P or CHR-N did not differ in their sociodemographic background, childhood adverse experiences or premorbid adjustment. In terms of premorbid functioning, subjects with CHR-P did not differ from 
patients with first-episode psychosis or multiepisode schizophrenia [49].

At baseline, the functioning of patients with FEP was poorer than that of patients with CHR-P and CHR-N, but this difference became equalized during follow-up; functioning improved in patients with FEP and CHR-P, but not in patients with CHR-N. In patients with FEP, resolving psychotic symptoms were associated with reduced functioning in the acute phase (Supplementary Table 2) and possibly explained their good functional recovery. In patients with CHR-P, the recovery of functioning was slower and was not related to psychotic symptoms. Instead, negative and disorganization symptoms were significantly associated with functioning at baseline and at the 9-month follow-up visit, but not at the 18-month follow-up (Supplementary Table 2), indicating that improvements in negative and disorganization symptoms were possibly related to improvements in functional outcomes. The interventions possibly focused on reducing positive psychotic symptoms did not considerably improve functioning in patients with CHR-N.

At the eighteen-months follow-up, $43.4 \%$ of patients with FEP functioned well, 29.5\% functioned moderately, and $27.1 \%$ functioned poorly. The proportion of patients with good functioning was slightly higher than that reported in previous studies [81, 82]. Remarkably, the sociodemographic background, SIPS symptoms, neurocognitive deficits and premorbid adjustment were extensively associated with functioning. However, in the multivariate model, only basic education (high), work situation (good), disorganization symptoms (few), perceptual disturbances (few) and late adolescence premorbid adjustment (good) predicted significantly good functional outcomes. However, constructions of predictive factors for functional outcome varied considerably between patients with FEP, CHR-P and CHR-N.

In patients with FEP, the marital status (single), poor basic education and poor work situation were strongly associated with a poor functional outcome. Marital status, education and work situation, central components of social competence [83, 84] represent endpoints of psychosocial development at the beginning of the first visit for treatment. Interestingly, these three sociodemographic factors were still powerful predictors, although the effect of adolescent development [64] was considered. Possibly since adolescence, psychiatric symptomatology and neuropsychological deficits with difficulties in schooling shift both sociosexual and work performance development to the low competence trajectory with further worsening after the onset of psychosis. In patients with chronic schizophrenia, extremely low competence was observed in single men whose quality of life was exceptionally low [85].
In patients with CHR-P and CHR-N, the roles of education and work situation varied, as the latter was a significant predictor, but not the former. In our previous studies on patients with CHR-P $[60,86]$, the work situation and education predicted functioning at the shortterm follow-up. In the present study, the small number of patients with CHR-P may explain the difference; in a combined sample, both education and the work situation were significant predictors (analyses available by request), indicating that they are both important predictors of functioning in patients with subclinical psychotic symptoms.

Among the baseline symptoms, only SIPS disorganization symptoms displayed power in independently predicting functional outcomes of both patients with FEP and CHR-P. The effect of negative symptoms on functioning, which has been reported in several studies on patients with schizophrenia $[15,17,18,20,22]$ and in bivariate analyses of the present study, was replaced by the effects of work situation and disorganization symptoms. Positive symptoms correlated with baseline functioning, but in the model, they did not significantly predict functioning at follow-up. In a follow-up study of patients with FEP, remission of negative symptoms was a critical predictor of future functioning [81]. Consistent with earlier studies [20, 22, 60, 87], the prevention of major psychotic symptoms, delusions and hallucinations, hardly exert a substantial effect on the functional outcomes of patients with psychosis. In patients with CHR-P, the role of positive symptoms is similar. Similar to our previous studies $[60,86]$ examining patients with CHR-P, positive symptoms and the transition to psychosis were not associated with functional outcomes. Positive psychotic symptoms (such as delusions and hallucinations) are specific predictors of new or incident psychotic disorders [88-90], but they rarely play any role in predicting functional outcomes of patients with CHR-P.

In bivariate analyses, various neurocognitive deficit indicators were associated with functional outcomes, but in the multivariate model, only perceptual disturbances, as assessed using the Rorschach Exner (RCS) test, were specifically independently associated with poor functional outcomes in patients with FEP. This type of disturbance in visual form perceptions differs from sensory disturbances, such as hallucinations. Interestingly, deficits in visual learning (BVMT-R) were also associated with poor functional outcomes, but in model, they lost their predictive power when premorbid adjustment was entered into the model. Perceptual disturbances, possibly caused by the incoherent structure and function of the CNS neuronal network, appear to play an important role in functional outcomes among patients with psychosis. In patients with CHR-P and CHR-N, neurocognitive 
deficits played a minor role in predicting the functional outcome. Thus, although neurocognitive deficits are common in patients with FEP [23-28] and CHR$\mathrm{P}$ [47-54] and correlate with actual functioning, their value in predicting functional outcomes is not great.

Consistent with earlier studies [14-22, 60], premorbid adjustment, assessed using the PAS scale, was strongly associated with functional outcomes in patients with FEP and CHR-P. In both patient groups, late adolescence PAS scores had the strongest association with functioning at follow-up. The first signs of schizophrenia often occur in adolescence. While the PAS assessment represents a global assessment of individuals' early psychosocial development, it also includes the effects of genetic and environmental factors, such as childhood adversities.

Remarkably, although childhood adversities were associated with the onset of psychotic and subpsychotic disorders, such as CHR [30-33, 56, 57], and with the transition to psychosis in patients with CHR [91], they did not predict functioning at follow-up in the multivariate model used in the present study.

Similar to other studies on patients with CHR-P [45, 92], affective disorders, both depression and anxiety were very common at the time the patients sought help. During follow-up, the transition to psychosis was not associated with functioning, and the association of positive psychotic symptoms was slight, while depressive and anxiety symptoms were strongly associated with poorer functioning and greatly increased the predictive power of the model. Based on these findings, affective and not positive psychotic symptomatology is the major psychiatric symptomatology worsening functional outcomes in patients with CHR-P. Additionally, in other studies of patients with CHR-P, a nonpsychotic comorbidity was associated with poor functional outcomes [93, 94].

A comparison of short-term functional outcomes between patients with FEP and CHR-P suggests that they may represent qualitatively different groups of helpseekers. Individuals with FEP form a heterogeneous group of patients with psychosis, among whom previous psychosocial and educational development and disorganization symptoms are decisive clinical factors predicting functional outcomes. Help-seekers with CHR$\mathrm{P}$ represent individuals suffering from long-term affective disorders with mostly temporary distress that increases psychotic-like symptoms. In both groups of patients, resolving positive symptoms correlated with a functional improvement, while the continuation of affective (depression and anxiety) symptoms seemed to prevent further improvement in functioning. In patients with CHR-N, subclinical positive symptoms are mild, and functional recovery is minor. In all three patient groups, the ability to work at the time of the first visit for treatment was considerably reduced and greatly predicted their future functioning.

\section{Conclusions and implications}

At the end of follow-up, the functional outcomes of patients with FEP improved considerably to the same level as in patients with CHR-N, whose functioning did not improve significantly. More than $90 \%$ of patients with FEP received antipsychotic medication, which probably improved the lower functioning of patients with FEP related to positive psychotic symptoms.

In addition to poor premorbid adjustment and disorganization symptomatology, poor education and work situations were associated with poor functional outcomes in patients with clinical or subclinical psychotic symptoms. Thus, psychosocial interventions aiming to improve studying and working abilities are needed to improve the future functioning of patients with severe psychotic and nonpsychotic disorders [95]. Support for education and employment considerably improve school participation and the ability to work of patients with FEP [96], and individual placement and support improve the ability to work and succeed in school, leading to competitive employment compared with traditional vocational rehabilitation [97]. Neurocognitive remediation combined with supported employment may further improve the working ability of patients with a severe mental illness [98-100]. Interventions aimed at treating depression-anxiety syndrome may improve functional outcomes, particularly in patients with CHR-P.

\section{Supplementary Information}

The online version contains supplementary material available at https://doi. org/10.1186/s12888-021-03516-4.

\section{Additional file 1.}

Additional file 2: Supplementary Table 1. Repeated bivariate measure ANOVA of functional outcomes for sociodemographic characteristics by diagnostic groups. Significant $p$ values bolded.

Additional file 3: Supplementary Table 2. Repeated bivariate ANOVA of functional outcomes for baseline symptoms (SIPS), childhood adverse and trauma experiences (TADS).

Additional file 4: Supplementary Table 3. Repeated bivariate measures ANOVA of functional outcomes for neuropsychological tests by diagnostic groups. Significant associations bolded.

Additional file 5: Supplementary Table 4a. Repeated measures ANOVA of functional outcome for patients with first-episode psychosis (FEP, $n=105$ ). Supplementary Table $\mathbf{4 b}$. Repeated measures ANOVA of functional outcomes for patients with confirmed clinical high-risk to psychosis (CHR-P, $n=49)$. Supplementary Table 4c. Repeated measures ANOVA of functional outcome for patients with nonconfirmed clinical high-risk to psychosis (CHR-N, $n=40)$.

Acknowledgements

The authors would like to thank Mirka Kolkka, Anu Ellilä, Akseli Mäkelä, Otto Turtonen, Maarit Lehtinen, Henri Pesonen, Maria Tikka and Antti Luutonen for their valuable work in the TEPS study. 


\section{Authors' contributions}

R.K.R.S. and J.H. Study planning and leadership, data analysis, and manuscript writing. T.F. Data management and quality control, participating in the coordination of examinations, and participating in data analyses and manuscript writing. T.I. Neuropsychological testing and participating in writing. S.L. and M.H. Participating in study planning, assessment of the results and manuscript writing. R-L.A. and H.L. Neuroimaging and assessment of results, and participating in writing the manuscript. M.W. Participating in the assessment of results and commenting on the manuscript. J.P. and A.T. Data collection (interviews) and neuropsychological testing. P.J. Coordination of examinations, data collection (interviews), and quality control. L.T. Participating in the assessment of results and in writing the manuscript. All authors approved the final manuscript as submitted.

\section{Funding}

TEPS has been funded by the EVO Funding of Turku City Health Care and Turku University Hospital (grant nos. TEPS600083, P13196, P3860, and P3848) and by the Academy of Finland (grant nos. 278155 and 278171).

\section{Availability of data and materials}

The TEPS dataset is not available for ethical reasons. The study information provided to the participants and the informed consent form they have signed includes a statement that the data collected will be used only for this particular study, not for other purposes.

\section{Declarations}

\section{Ethics approval and consent to participate}

The TEPS study program was carried out in accordance with the latest version of the Declaration of Helsinki. The study design and protocols were approved by the ethics committee of Turku University Hospital. Written informed consent was obtained from participants after the procedure had been fully explained to them.

\section{Consent for publication}

Not applicable.

\section{Competing interests}

The authors have no competing interests to declare.

\section{Author details}

'Department of Psychiatry, University of Turku, Kunnallissairaalantie 20, FIN-20700 Turku, Finland. ${ }^{2}$ Department of Psychiatry, Turku University Hospital, Turku, Finland. ${ }^{3}$ Royal Ottawa Mental Health Centre, Ottawa, Canada.

Received: 14 April 2021 Accepted: 28 September 2021

Published online: 02 December 2021

\section{References}

1. WHO. The Global Burden of Disease: Update 2008. http://www.who.int/ topics/global_burden_of_disease/en/ Assessed 22 Mar 2021.

2. Gustavsson A, Svensson M, Jacobi F, Allgulander C, Alonso J, Beghi E, et al. CDBE2010 study group. Cost of disorders of the brain in Europe 2010. Eur Neuropsychopharmacol. 2011;21(10):718-79. https://doi.org/10.1016/j. euroneuro.2011.08.008

3. Saha S, Chant D, McGrath J. A systematic review of mortality in schizophrenia: is the differential mortality gap worsening over time? Arch Gen Psychiatry. 2007;64(10):1123-31. 17909124. https://doi.org/10.1001/a rchpsyc.64.10.1123

4. Kelly C, McCreadie RG, MacEwan T, Carey S. Nithsdale schizophrenia surveys. 17. Fifteen year review. Br J Psychiatry. 1998;172(6):513-7. 9828992. https:// doi.org/10.1192/bjp.172.6.513

5. Jääskeläinen $E$, Juola $P$, Hirvonen $N$, et al. A systematic review and metaanalysis of recovery in schizophrenia. Schizophr Bull. 2013;39(6):1296-306. https://doi.org/10.1093/schbul/sbs130 Epub 2012 Nov 20. PMID: 23172003; PMCID: PMC3796077.

6. Brown S, Birtwistle J, Roe L, Thompson C. The unhealthy lifestyle of people with schizophrenia. Psychol Med. 1999;29(3):697-701. https://doi.org/10.10 7/s0033291798008186 PMID: 10405091.
7. Honkonen T, Stengård E, Virtanen M, Salokangas RK. Employment predictors for discharged schizophrenia patients. Soc Psychiatry Psychiatr Epidemiol. 2007:42(5):372-80. https://doi.org/10.1007/s00127-007-0180-5 Epub 2007 Mar 19. PMID: 17492406

8. Jobe $T H$, Harrow M. Long-term outcome of patients with schizophrenia: a review. Can J Psychiatr. 2005;50(14):892-900. 16494258. https://doi.org/10.11 77/070674370505001403.

9. Vaillant GE. The prediction of recovery in schizophrenia. J Nerv Ment Dis. 1962;135(6):534-43. https://doi.org/10.1097/00005053-196212000-00006 PMID: 13995749

10. Astrup C, Noreik K. Functional psychoses. Diagnostic and prognostic models. Springfield: Charles C Thomas; 1966. p. 176.

11. Noreik K, Astrup C, Dalgard OS, Holmboe R. A prolonged follow-up of acute schizophrenic and schizophreniform psychoses. Acta Psychiatr Scand. 1967; 43(4):432-43. https://doi.org/10.1111/j.1600-0447.1967.tb05780.x.

12. Stephens JH, Astrup C, Mangrum JC. Prognosis in schizophrenia. Prognostic scales cross validated in American and Norwegian patients. Arch Gen Psychiatry. 1967;16(6):693-8. https://doi.org/10.1001/archpsyc.1967.0173024 0049008 PMID: 6027367

13. Stephens $\mathrm{JH}$. Long-term prognosis and follow up in schizophrenia. Schizophr Bull. 1978;4(1):25-47. https://doi.org/10.1093/schbul/4.1.25 PMID: 34208.

14. Salokangas RKR. Skitsofreniaan sairastuneiden psykososiaalinen kehitys. (English summary: the psychosocial development of schizophrenic patients.) Kansaneläkelaitoksen julkaisuja AL 7. Turku: Kansaneläkelaitos; 1977.

15. Salokangas RKR. Psychosocial prognosis in schizophrenia. Formation of the prognosis for schizophrenic patients: a multivariate analysis. Annales Universitatis Turkuensis. Ser. D. Turku: University of Turku; 1978.

16. Salokangas RK. Prognostic implications of the sex of schizophrenic patients. Br J Psychiatry. 1983;142(2):145-51. https://doi.org/10.1192/bjp.142.2.145 PMID: 6839067.

17. Salokangas RKR. Skitsofrenian hoito ja ennuste. (English Summary Treatment and outcome in schizophrenia. Kansanterveystieteen julkaisuja M 89/85. University of Tampere Community Health Institute, University of Turku. Tampere; 1985.

18. Salokangas RK, Stengård E. Gender and short-term outcome in schizophrenia. Schizophr Res. 1990;3(5-6):333-45. https://doi.org/10.1016/ 0920-9964(90)90019-4 PMID: 2282339.

19. Salokangas RKR, Stengård E, Räkköläinen V, Alanen YO, Kaljonen A. Treatment and Outcome of New Patients with Schizophrenia. Five-year Outcome [NSP project] (In Finnish: Uusien skitsofreniapotilaiden hoito ja ennuste [USP-projekti] V: Viiden vuoden ennuste. Reports of Psychiatria Fennica No 95. Helsinki; 1991.

20. Möller HJ, von Zerssen D. Course and outcome. In: Hirsch SR, Weinberger DR, editors. Schizophrenia. Oxford: Blackwell Science; 1995. p. 106-27.

21. Green MF, Kern RS, Braff DL, Mintz J. Neurocognitive deficits and functional outcome in schizophrenia: are we measuring the "right stuff"? Schizophr Bull. 2000;26(1):119-36. https://doi.org/10.1093/oxfordjournals.schbul.a03343 O PMID: 10755673

22. White C, Stirling J, Hopkins R, Morris J, Montague L, Tantam D, et al. Predictors of 10-year outcome of first-episode psychosis. Psychol Med. 2009; 39(9):1447-56. https://doi.org/10.1017/S003329170800514X Epub 2009 Feb 3. PMID: 19187566.

23. Pantelis C, Yücel M, Wood SJ, McGorry PD, Velakoulis D. Early and late neurodevelopmental disturbances in schizophrenia and their functional consequences. Aust N Z J Psychiatry. 2003;37(4):399-406. https://doi.org/1 0.1046/j.1440-1614.2003.01193.x PMID: 12873323.

24. Carpenter WT, Bustillo JR, Thaker GK, van Os J, Krueger RF, Green MJ. The psychoses: cluster 3 of the proposed meta-structure for DSM-V and ICD-11. Psychol Med. 2009;39(12):2025-42. https://doi.org/10.1017/S00332917099902 86 Epub 2009 Oct 1. PMID: 19796428.

25. Rosell DR, Futterman SE, McMaster A, Siever L. Schizotypal personality disorder: a current review. Curr Psychiatry Rep. 2014;16(7):452. https://doi. org/10.1007/s11920-014-0452-1 PMID: 24828284; PMCID: PMC4182925.

26. Bortolato B, Miskowiak KW, Köhler CA, Vieta E, Carvalho AF. Cognitive dysfunction in bipolar disorder and schizophrenia: a systematic review of meta-analyses. Neuropsychiatr Dis Treat. 2015;1 1:3111-25. https://doi.org/1 0.2147/NDT.S76700 eCollection 2015.

27. Bora E, Pantelis C. Social cognition in schizophrenia in comparison to bipoLar disorder: a meta-analysis. Schizophr Res. 2016;175(1-3):72-8. https:// doi.org/10.1016/j.schres.2016.04.018. 
28. Green MF, Horan WP, Lee J. Nonsocial and social cognition in schizophrenia: current evidence and future directions. World Psychiatry. 2019;18(2):146-61. https://doi.org/10.1002/wps.20624 PMID: 31059632; PMCI D: PMC6502429.

29. Stirling J, White C, Lewis S, Hopkins R, Tantam D, Huddy A, et al. Neurocognitive function and outcome in first-episode schizophrenia: a 10year follow-up of an epidemiological cohort. Schizophr Res. 2003;65(2-3): 75-86. https://doi.org/10.1016/s0920-9964(03)00014-8 PMID: 14630300

30. Varese F, Smeets F, Drukker M, et al. Childhood adversities increase the risk of psychosis: a meta-analysis of patient-control, prospective- and crosssectional cohort studies. Schizophr Bull. 2012;38(4):661-71. https://doi.org/1 0.1093/schbul/sbs050 Epub 2012 Mar 29. PMID: 22461484; PMCID: PMC3406538.

31. Bonoldi I, Simeone E, Rocchetti M, Codjoe L, Rossi G, Gambi F, et al. Prevalence of self-reported childhood abuse in psychosis: a meta-analysis of retrospective studies. Psychiatry Res. 2013;210(1):8-15. https://doi.org/10.101 6/j.psychres.2013.05.003 Epub 2013 Jun 20. PMID: 23790604

32. Trauelsen AM, Bendall S, Jansen JE, Nielsen HGL, Pedersen MB, Trier $\mathrm{CH}_{\text {, }}$ et al. Childhood adversity specificity and dose-response effect in nonaffective first-episode psychosis. Schizophr Res. 2015;165(1):52-9. https://doi. org/10.1016/j.schres.2015.03.014 Epub 2015 Apr 11. PMID: 25868932

33. Salokangas RKR, Schultze-Lutter F, Schmidt SJ, Pesonen H, Luutonen S, Patterson $\mathrm{P}$, et al. Childhood physical abuse and emotional neglect are specifically associated with adult mental disorders. J Ment Health. 2020; 29(4):376-84. https://doi.org/10.1080/09638237.2018.1521940 Epub 2019 Jan 24. PMID: 30675805

34. Yung AR, Phillips $L$, McGorry PD, et al. Prediction of psychosis. A step towards indicated prevention of schizophrenia. Br J Psychiatry Suppl. 1998; 172(33):14-20. https://doi.org/10.1192/S0007125000297602 PMID: 9764121.

35. Klosterkötter J, Hellmich M, Steinmeyer EM, Schultze-Lutter F. Diagnosing schizophrenia in the initial prodromal phase. Arch Gen Psychiatry. 2001; 58(2):158-64. https://doi.org/10.1001/archpsyc.58.2.158 PMID: 11177117.

36. Miller TJ, McGlashan TH, Rosen $J$, et al. Prospective diagnosis of the initial prodrome for schizophrenia based on the structured interview for prodromal syndromes: preliminary evidence of interrater reliability and predictive validity. Am J Psychiatry. 2002;159(5):863-5. https://doi.org/10.11 76/appi.ajp.159.5.863 PMID: 11986145.

37. Fusar-Poli P, Bonoldi I, Yung AR, Borgwardt S, Kempton MJ, Valmaggia L, et al. Predicting psychosis: meta-analysis of transition outcomes in individuals at high clinical risk. Arch Gen Psychiatry. 2012;69(3):220-9. https://doi.org/10.1001/archgenpsychiatry.2011.1472 PMID: 22393215.

38. Fusar-Poli P, Cappucciati M, Borgwardt S, Woods SW, Addington J, Nelson B, et al. Heterogeneity of psychosis risk within individuals at clinical high risk: a Meta-analytical stratification. JAMA Psychiatry. 2016;73(2):113-20. https://doi. org/10.1001/jamapsychiatry.2015.2324.

39. Schmidt SJ, Schultze-Lutter F, Schimmelmann BG, Maric NP, Salokangas RKR, Riecher-Rössler A, et al. EPA guidance on the early intervention in clinical high risk states of psychoses. Eur Psychiatry. 2015;30(3):388-404. https://doi. org/10.1016/j.eurpsy.2015.01.013 Epub 2015 Mar 3.

40. Fusar-Poli P, Salazar de Pablo G, Correll CU, et al. Prevention of Psychosis: Advances in Detection, Prognosis, and Intervention. JAMA Psychiatry. 77(7): 755-65. https://doi.org/10.1001/jamapsychiatry.2019.4779.

41. Yung AR, Phillips LJ, Yuen HP, Francey SM, McFarlane CA, Hallgren M, et al. Psychosis prediction: 12-month follow up of a high-risk ("prodromal") group. Schizophr Res. 2003;60(1):21-32. https://doi.org/10.1016/s0920-9964(02)001 67-6 PMID: 12505135.

42. Cannon TD, Cadenhead K, Cornblatt B, Woods SW, Addington J, Walker E, et al. Prediction of psychosis in youth at high clinical risk: a multisite longitudinal study in North America. Arch Gen Psychiatry. 2008;65(1):28-37. https://doi.org/10.1001/archgenpsychiatry.2007.3.

43. Ruhrmann S, Schultze-Lutter F, Salokangas RK, et al. Prediction of psychosis in adolescents and young adults at high risk: results from the prospective European prediction of psychosis study. Arch Gen Psychiatry. 2010;67(3): 241-51. https://doi.org/10.1001/archgenpsychiatry.2009.206 PMID: 20194824.

44. Dragt S, Nieman DH, Schultze-Lutter F, van der Meer F, Becker H, de Haan L, et al. Cannabis use and age at onset of symptoms in subjects at clinical high risk for psychosis. Acta Psychiatr Scand. 2012;125(1):45-53. https://doi. org/10.1111/j.1600-0447.2011.01763.x Epub 2011 Aug 29. PMID: 21883099.

45. Fusar-Poli P, Nelson B, Valmaggia L, Yung AR, McGuire PK. Comorbid depressive and anxiety disorders in 509 individuals with an at-risk mental state: impact on psychopathology and transition to psychosis. Schizophr
Bull. 2014;40(1):120-31. https://doi.org/10.1093/schbul/sbs136 Epub 2012 Nov 22. PMID: 23180756; PMCID: PMC3885287.

46. Salokangas RK, Dingemans P, Heinimaa M, EPOS group, et al. Prediction of psychosis in clinical high-risk patients by the schizotypal personality questionnaire. Results of the EPOS project. Eur Psychiatry. 2013a;28(8):469-75. https://doi.org/10.101 6/j.eurpsy.2013.01.001 Epub 2013 Feb 8. PMID: 23394823.

47. Bolt LK, Amminger GP, Farhall J, McGorry PD, Nelson B, Markulev C, et al. Neurocognition as a predictor of transition to psychotic disorder and functional outcomes in ultra-high risk participants: findings from the NEURAPRO randomized clinical trial. Schizophr Res. 2019;206:67-74. https:// doi.org/10.1016/j.schres.2018.12.013 Epub 2018 Dec 14.

48. Niendam TA, Bearden CE, Johnson JK, McKinley M, Loewy R, O'Brien M, et al. Neurocognitive performance and functional disability in the psychosis prodrome. Schizophr Res. 2006;84(1):100-11. https://doi.org/10.1016/j. schres.2006.02.005.

49. Addington J, Penn D, Woods SW, Addington D, Perkins DO. Social functioning in individuals at clinical high risk for psychosis. Schizophr Res. 2008;99(1-3):119-24. https://doi.org/10.1016/j.schres.2007.10.001 Epub 2007 Nov 19. PMID: 18023329; PMCID: PMC2292799.

50. Eslami A, Jahshan C, Cadenhead KS. Disorganized symptoms and executive functioning predict impaired social functioning in subjects at risk for psychosis. J Neuro-Oncol. 2011;23(4):457-60. https://doi.org/10.1176/appi. neuropsych.23.4.457.

51. Lin A, Wood SJ, Nelson B, Brewer WJ, Spiliotacopoulos D, Bruxner A, et al. Neurocognitive predictors of functional outcome two to 13 years after identification as ultra-high risk for psychosis. Schizophr Res. 2011;132(1):1-7. https://doi.org/10.1016/j.schres.2011.06.014 Epub 2011 Jul 16. PMID: 21763109.

52. Carrión RE, McLaughlin D, Goldberg TE, et al. Prediction of functional outcome in individuals at clinical high risk for psychosis. JAMA Psychiatry. 2013;70(11):1133-42. https://doi.org/10.1001/jamapsychiatry.2013.1909 PMID: 24006090; PMCID: PMC4469070.

53. Glenthøj LB, Fagerlund B, Hjorthøj C, Jepsen JRM, Bak N, Kristensen TD, et al. Social cognition in patients at ultra-high risk for psychosis: what is the relation to social skills and functioning? Schizophr Res Cogn. 2016;5:21-7. https://doi.org/10.1016/j.scog.2016.06.004.

54. Modinos G, Kempton MJ, Tognin S, EU-GEl High Risk Study Group, et al. Association of Adverse Outcomes With Emotion Processing and Its Neural Substrate in Individuals at Clinical High Risk for Psychosis. JAMA Psychiatry. 2020;77(2):190-200. https://doi.org/10.1001/jamapsychiatry.2019.3501 PMID: 31722018; PMCID: PMC6865249.

55. Cotter J, Drake RJ, Bucci S, Firth J, Edge D, Yung AR. What drives poor functioning in the at-risk mental state? A systematic review. Schizophr Res. 2014;159(2-3): 267-77. https://doi.org/10.1016/j.schres.2014.09.012 Epub 2014 Sep 24.

56. Addington J, Stowkowy J, Cadenhead KS, et al. Early traumatic experiences in those at clinical high risk for psychosis. Early Interv Psychiatry. 2013;7(3): 300-5. https://doi.org/10.1111/eip.12020 Epub 2013 Jan 24. PMID: 23343384; PMCID: PMC3754436.

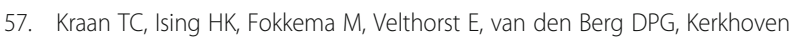
$M$, et al. The effect of childhood adversity on 4-year outcome in individuals at ultra high risk for psychosis in the Dutch early detection intervention evaluation (EDIE-NL) trial. Psychiatry Res. 2017;247:55-62. https://doi.org/10.1 016/j.psychres.2016.11.014 Epub 2016 Nov 11. PMID: 27863320.

58. Kraan T, van Dam DS, Velthorst E, et al. Childhood trauma and clinical outcome in patients at ultra-high risk of transition to psychosis. Schizophr Res. 2015;169(1-3):193-8. https://doi.org/10.1016/j.schres.2015.10.030 Epub 2015 Nov 14. PMID: 26585219.

59. RKR S, Patterson P, Hietala J, EPOS group, et al. Childhood adversity predicts persistence of suicidal thoughts differently in females and males at clinical high-risk patients of psychosis. Results of the EPOS project. Early Interv Psychiatry. 2019;13(4):935-42. https://doi.org/10.1111/eip.12714 Epub 2018 Jul 23. PMID: 30033690.

60. Salokangas RK, Heinimaa M, From T, EPOS group, et al. Short-term functional outcome and premorbid adjustment in clinical high-risk patients. Results of the EPOS project. Eur Psychiatry. 2014;29(6):371-80. https://doi. org/10.1016/j.eurpsy.2013.10.003 Epub 2013 Dec 7. PMID: 24315804.

61. Koutsouleris N, Kambeitz-Ilankovic L, Ruhrmann S, PRONIA Consortium, et al. Prediction Models of Functional Outcomes for Individuals in the Clinical High-Risk State for Psychosis or With Recent-Onset Depression: A Multimodal, Multisite Machine Learning Analysis. JAMA Psychiatry. 2018;75(11): 1156-72. https://doi.org/10.1001/jamapsychiatry.2018.2165 Erratum in: JAMA Psychiatry. 2019 May 1;76(5):550. PMID: 30267047; PMCID: PMC6248111. 
62. First MB, Spitzer RL, Gibbon M, Williams JBW. Structured clinical interview for DSM-IV-TR Axis I disorders, research version, patient edition. New York: Biometrics Research, New York State Psychiatric Institute; 2002. (SCID-I/P)

63. McGlashan TH, Miller TJ, Woods SW. Structured interview for prodromal syndromes. Version 3.0 Connecticut. New Haven: Yale School of Medicine, PRIME Research Clinic; 2001.

64. McGlashan T, Walsh B, Woods S. The psychosis-risk syndrome: handbook for diagnosis and follow-up. Oxford: Oxford University Press; 2010.

65. Cannon-Spoor HE, Potkin SG, Wyatt RJ. Measurement of premorbid adjustment in chronic schizophrenia. Schizophr Bull. 1982;8(3):470-84. https://doi.org/10.1093/schbul/8.3.470.

66. Patterson P, Skeate A, Schultze-Lutter F, Graf von Reventlow H, Wieneke A, Ruhrmann $\mathrm{S}$, et al. The trauma and distress scale. Birmingham: University of Birmingham; 2002

67. Salokangas RKR, Schultze-Lutter F, Patterson P, von Reventlow HG, Heinimaa M, From T, et al. Psychometric properties of the Trauma and Distress Scale, TADS, in an adult community sample in Finland. Eur J Psychotraumatol. 2016;7(1):30062. https://doi.org/10.3402/ejpt.v7.30062.

68. Blumenthal JA, Burg MM, Barefoot J, Williams RB, Haney T, Zimet G. Social support, type a behavior, and coronary artery disease. Psychosom Med. 1987:49(4):331-40. https://doi.org/10.1097/00006842-198707000-00002 PMID: 3615762.

69. Wechsler D. Wechsler adult intelligence scale - III, Cleveland. Ohio: The psychological corporation; 2005. Finnish translation. Helsinki: Psykologien Kustannus Oy

70. Blair JR, Spreen O. Predicting premorbid IQ: a revision of the National Adult Reading Test. Clin Neuropsychol. 1989;3(2):129-36. https://doi.org/10.1 080/13854048908403285.

71. Spreen O, Strauss E. A compendium of neuropsychological tests. New York: Oxford University Press; 1998.

72. Reitan RM. TMT, trail making test a \& B; 1992.

73. Wechsler D. Wechsler memory scale (3rd ed.) the psychological corporation, Harcourt brace Jovanovich, New York. Finnish translation. Psykologien Kustannus Oy: Helsinki; 2008.

74. Brandt J, Benedict RHB. Hopkins verbal learning test - revised. Administration manual. Psychological Assessment Resources: Lutz FL; 2001

75. Benedict RHB. Brief visuospatial memory test - revised: professional manual. Psychological Assessment Resources Inc: Lutz, FL; 1997

76. White T, Stern RA. Neuropsychological assessment battery (NAB): demographically corrected norms manual. Psychological Assessment Resources Inc: Lutz, FL; 2003.

77. Exner JE. The Rorschach: a comprehensive system. Vol. 1, 4th edition, basic foundations basic foundations and principles of interpretation. New York: Wiley; 2003.

78. Mihura JL, Meyer GJ, Dumitrascu N, Bombel G. The validity of individual Rorschach variables: systematic reviews and meta-analyses of the comprehensive system. Psychol Bull. 2013;139(3):548-605. https://doi.org/1 0.1037/a0029406 Epub 2012 Aug 27. PMID: 22925137.

79. Heaton RK, Chelune GJ, Talley JL, Kay GG, Curtiss G. Wisconsin card sorting test manual: revised and expanded. Psychological Assessment Resources: Odessa, FL; 1993.

80. Mayer JD, Salovey P, Caruso D. MSCEIT technical manual. Toronto: MultiHealth Systems; 2002.

81. Cassidy CM, Norman R, Manchanda R, Schmitz N, Malla A. Testing definitions of symptom remission in first-episode psychosis for prediction of functional outcome at 2 years. Schizophr Bull. 2010;36(5):1001-8. https://doi.org/10.1093/ schbul/sbp007 Epub 2009 Mar 25. PMID: 19321629; PMCID: PMC2930352.

82. Lally J, Ajnakina O, Stubbs B, Cullinane M, Murphy KC, Gaughran F, et al. Remission and recovery from first-episode psychosis in adults: systematic review and meta-analysis of long-term outcome studies. Br J Psychiatry. 2017;211(6):350-8. https://doi.org/10.1192/bjp.bp.117.201475 Epub 2017 Oct 5. PMID: 28982659

83. Zigler E, Phillips L. Social competence and outcome in psychiatric disorders. J Abnorm Soc Psychol. 1961;63(2):264-71. https://doi.org/10.1037/h0046232.

84. Zigler E, Phillips L. Social competence and the process-reactive distinction in psychopathology. J Abnorm Soc Psychol. 1962;65(4):215-22. https://doi. org/10.1037/h0040765 PMID: 14003638

85. Salokangas RK, Honkonen T, Stengård E, Koivisto AM. To be or not to be married--that is the question of quality of life in men with schizophrenia. Soc Psychiatry Psychiatr Epidemiol. 2001;36(8):381-90. 11766968. https://doi. org/10.1007/s001270170028.
86. Salokangas RK, Nieman DH, Heinimaa M, EPOS group, et al. Psychosocial outcome in patients at clinical high risk of psychosis: a prospective followup. Soc Psychiatry Psychiatr Epidemiol. 2013b;48(2):303-11. https://doi.org/1 0.1007/s00127-012-0545-2 Epub 2012 Jul 15. PMID: 22797132.

87. Ventura J, Hellemann GS, Thames AD, Koellner V, Nuechterlein KH. Symptoms as mediators of the relationship between neurocognition and functional outcome in schizophrenia: a meta-analysis. Schizophr Res. 2009; 113(2-3):189-99. https://doi.org/10.1016/j.schres.2009.03.035 Epub 2009 Jul 22. PMID: 19628375; PMCID: PMC2825750.

88. Webb JR, Addington J, Perkins DO, et al. Specificity of Incident Diagnostic Outcomes in Patients at Clinical High Risk for Psychosis. Schizophr Bull. 2015;41(5):1066-75. https://doi.org/10.1093/schbul/sbv091 Erratum in: Schizophr Bull. 2018;44(4):933-935. PMID: 26272875; PMCID: PMC4535651.

89. Fusar-Poli P, Rutigliano G, Stahl D, Davies C, de Micheli A, Ramella-Cravaro V, et al. Long-term validity of the at risk mental state (ARMS) for predicting psychotic and non-psychotic mental disorders. Eur Psychiatry. 2017;42:4954. https://doi.org/10.1016/j.eurpsy.2016.11.010 Epub 2016 Dec 6. PMID: 28212505.

90. Woods SW, Powers AR 3rd, Taylor JH, et al. Lack of Diagnostic Pluripotentiality in Patients at Clinical High Risk for Psychosis: Specificity of Comorbidity Persistence and Search for Pluripotential Subgroups. Schizophr Bull. 2018;44(2):254-63. https://doi.org/10.1093/schbul/sbx138 PMID: 29036402; PMCID: PMC5814797.

91. Kraan TC, Velthorst E, Themmen M, EU-GEl High Risk Study, et al. Child Maltreatment and Clinical Outcome in Individuals at Ultra-High Risk for Psychosis in the EU-GEl High Risk Study. Schizophr Bull. 2018;44(3):584-92. https://doi.org/10.1093/schbul/sbw162 PMID: 28666366; PMCID: PMC5890491.

92. Salokangas RK, Ruhrmann S, von Reventlow HG, EPOS group, et al. Axis I diagnoses and transition to psychosis in clinical high-risk patients EPOS project: prospective follow-up of 245 clinical high-risk outpatients in four countries. Schizophr Res. 2012;138(2-3):192-7. https://doi.org/10.1016/j. schres.2012.03.008 Epub 2012 Mar 31. PMID: 22464922.

93. Falkenberg I, Valmaggia L, Byrnes M, Frascarelli M, Jones C, Rocchetti M, et al. Why are help-seeking subjects at ultra-high risk for psychosis helpseeking? Psychiatry Res. 2015;228(3):808-15. https://doi.org/10.1016/j. psychres.2015.05.018 Epub 2015 May 30. PMID: 26071897.

94. Rutigliano G, Valmaggia L, Landi P, Frascarelli M, Cappucciati M, Sear V, et al. Persistence or recurrence of non-psychotic comorbid mental disorders associated with 6-year poor functional outcomes in patients at ultra high risk for psychosis. J Affect Disord. 2016;203:101-10. https://doi.org/10.1016/j. jad.2016.05.053 Epub 2016 May 31. PMID: 27285723.

95. Kahn RS, Sommer IE, Murray RM, Meyer-Lindenberg A, Weinberger DR, Cannon TD, et al. Schizophrenia. Nat Rev Dis Primers. 2015;1(1):15067. https://doi.org/10.1038/nrdp.2015.67 PMID: 27189524.

96. Rosenheck R, Mueser KT, Sint K, Lin H, Lynde DW, Glynn SM, et al. Supported employment and education in comprehensive, integrated care for first episode psychosis: effects on work, school, and disability income. Schizophr Res. 2017;182:120-8. https://doi.org/10.1016/j.schres.2016.09.024 Epub 2016 Sep 23. PMID: 27667369.

97. Modini M, Tan L, Brinchmann B, Wang MJ, Killackey E, Glozier N, et al. Supported employment for people with severe mental illness: systematic review and meta-analysis of the international evidence. Br J Psychiatry. 2016;209(1):14-22. https://doi.org/10.1192/bjp.bp.115.165092 Epub 2016 Apr 21. PMID: 27103678.

98. Bell MD, Bryson GJ, Greig TC, Fiszdon JM, Wexler BE. Neurocognitive enhancement therapy with work therapy: productivity outcomes at 6- and 12-month follow-ups. J Rehabil Res Dev. 2005;42(6):829-38. https://doi.org/1 0.1682/jrrd.2005.03.0061 PMID: 16680620.

99. Bell MD, Choi KH, Dyer C, Wexler BE. Benefits of cognitive remediation and supported employment for schizophrenia patients with poor community functioning. Psychiatr Serv. 2014;65(4):469-75. https://doi.org/10.1176/appi. ps.201200505 PMID: 24382594.

100. Chan JY, Hirai HW, Tsoi KK. Can computer-assisted cognitive remediation improve employment and productivity outcomes of patients with severe mental illness? A meta-analysis of prospective controlled trials. J Psychiatr Res. 2015;68:293-300. https://doi.org/10.1016/j.jpsychires.2015.05.010 Epub 2015 May 21. PMID: 26028551.

\section{Publisher's Note}

Springer Nature remains neutral with regard to jurisdictional claims in published maps and institutional affiliations. 